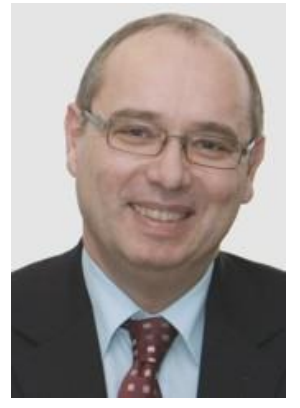

\title{
Current and Future Trends of the Automotive Industry
}

\author{
Prof. Dieter Schramm
}

Mobility, and especially individual physical mobility, is still an essential component of nearly all societies. The combustion engine was for more than a hundred years, and is still today, the backbone of road-based mobility. However, the guarantor for the triumphant advance of the combustion engine was by far not its technical superiority over its electrical rival at the beginning of the automobile era, but the energy density and the easy worldwide availability of fossil fuels as a means of energy storage. So, e.g. to store the energy equivalent of one $\mathrm{kg}$ Gasoline, a lithium ion battery with a mass of about $180 \mathrm{~kg}$ would be required (Schramm, 2012), even if the higher efficiency of the electric motor vs. the combustion engine is taken into account. Actually an electric motor is much better suited as a drive source for a motor vehicle as an internal combustion engine. Only the achievable energy density along with the cost of its chemical-process based storage, the battery, still prevent its immediate breakthrough in the automotive drive technology.

Nevertheless, the German Government has set the target to bring at least a million electrified motor vehicles on Germany's roads by 2020 , which is already impossible to reach from today's perspective. However, strategies are needed to achieve a sustainable transition to electric mobility. This, in addition to continued research on high-efficiency batteries which also includes the development of vehicles that offer a good compromise between coverage, costs and consumption while satisfying the mobility needs of their users.

Another trend that will lead to a paradigm shift in the use of individually-powered vehicles is the automation of the task of driving up to the highly automated or even autonomous vehicle. The technical prerequisites like sensors and actuators for these new systems are already available at least for application on motorways and rural regions, e.g. in Germany. More activities are required for robust algorithms and strategies to hand over control back to the driver in complex situations and even vice versa from the driver to the car in cases where the driver is unable to further control his car, e.g. in case of a heart attack. Another open field is the question of the responsibility in case of an accident along with even ethic problems.

A widely uncharted aspect is the individual customer who is expected and needed to buy the vehicle and his/her behaviour of vehicle use. For this reason currently a variety of activities is underway to find out how cars are actually being used in different countries. Those different usage scenarios would have a significant effect on the availability, environmental impact and economics notably of electrified vehicles. So a project funded by the German government is the Ruhr Car Sharing Project operated by the University of Duisburg-Essen and their partners for several years especially for electric and hybrid vehicles (Tewiele et al., 2015). Still unidentified, however, is the influence of a large proportion of electrified and highly automated vehicles on consumption, the total CO2 emissions and traffic jams (Jeschke et al., 2014). For this purpose extensive field experiments are conducted along with activities using simulation models to predict these impacts reliably for the future. It has to be made possible to successfully derive development strategies for Europe and other regions as well (Schüller et al., 2015).

Despite all difficulties, we are confident that there will be solutions for robust environment friendly technical solutions, acceptance by humans and even legal obstacles. As Albert Einstein once said, "Amid the difficulty lies opportunity." 


\title{
References
}

[1] Jeschke S, Hirsch H, Koppers M and Schramm D (2014) Investigations on the impact of different electric vehicle traction systems in urban traffic. In Vehicle Power and Propulsion Conference (VPPC) 2013, S 1 - 6 IEEE Beijing, China.

[2] Schramm D (2012) Diversity of Future Mobility - Automotive Landscape 2025. (ed.), Duisburg.

[3] Schüller M, Tewiele S, Bruckmann T and Schramm D (2015) Evaluation of alternative drive systems based on driving patterns comparing Germany, China and Malaysia. in 3rd International Conference on Recent Advances in Automotive Engineering \& Mobility Research (ReCar)(ed.), Malakka, Malaysia.

[4] Tewiele S, Schüller M, Koppers M and Schramm D (2015) Driving Pattern Analysis of Hybrid and Electric Vehicles in a German Conurbation including a Drive System Evaluation. in 3rd International Conference on Recent Advances in Automotive Engineering \& Mobility Research (ReCar)(ed.), Malakka, Malaysia.

\begin{abstract}
About Prof. Dieter Schramm
Dieter Schramm graduated in mathematics at the University of Stuttgart in 1981, worked there from 1981-1986 as a research assistant and received his PhD in Engineering in 1986. From 1986-1998 he worked at Robert Bosch GmbH as group leader and department head of predevelopment and series development departments for automotive systems. He joined Tyco Electronics Ltd.

in 1999 and held the positions of Director Global Automotive Engineering and later CEO of Tyco Electronics Pretema $\mathrm{GmbH}$ until 2003. In 2004 he was appointed Full Professor and head of the Chair of Mechatronics at the University of Duisburg-Essen and in 2006 he was elected Dean of the Faculty of Engineering. His current research interests are electrified and alternative fuel driven automobiles, driver assistance systems, vehicle dynamics and cable driven manipulators.
\end{abstract}

In 2015, he was awarded Dr. h.c. by the University of Miskolc, Hungary. Along with his research activities he is director and partner of several companies in the field of research and post graduated education. 